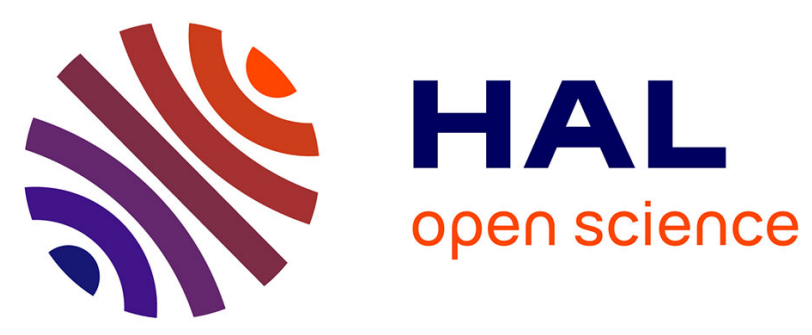

\title{
Double Walled Carbon Nanotube/Polymer Composites via in-situ Nitroxide Mediated Polymerisation of Amphiphilic Block Copolymers
}

Vitaliy Datsyuk, Christelle Guerret-Piecourt, Sylvie Dagréou, Laurent Billon, Jean-Charles Dupin, Emmanuel Flahaut, Alain Peigney, Christophe Laurent

\section{To cite this version:}

Vitaliy Datsyuk, Christelle Guerret-Piecourt, Sylvie Dagréou, Laurent Billon, Jean-Charles Dupin, et al.. Double Walled Carbon Nanotube/Polymer Composites via in-situ Nitroxide Mediated Polymerisation of Amphiphilic Block Copolymers. Carbon, 2004, 43 (4), pp.855-894. hal-00281668

\section{HAL Id: hal-00281668 \\ https://hal.science/hal-00281668}

Submitted on 23 May 2008

HAL is a multi-disciplinary open access archive for the deposit and dissemination of scientific research documents, whether they are published or not. The documents may come from teaching and research institutions in France or abroad, or from public or private research centers.
L'archive ouverte pluridisciplinaire HAL, est destinée au dépôt et à la diffusion de documents scientifiques de niveau recherche, publiés ou non, émanant des établissements d'enseignement et de recherche français ou étrangers, des laboratoires publics ou privés. 


\section{Double Walled Carbon Nanotube/Polymer Composites via in-situ Nitroxide Mediated}

\section{Polymerisation of Amphiphilic Block Copolymers}

Vitaliy Datsyuk, ${ }^{1}$ Christelle Guerret-Piecourt, ${ }^{1 *}$ Sylvie Dagreou, ${ }^{1}$ Laurent Billon, ${ }^{1}$ Jean-Charles Dupin, ${ }^{2}$ Emmanuel Flahaut, ${ }^{3}$ Alain Peigney, ${ }^{3}$ Christophe Laurent ${ }^{3}$

${ }^{1}$ Laboratoire de Physico-Chimie des Polymères - UMR-CNRS 5067, and ${ }^{2}$ Laboratoire de Physico-

Chimie Moléculaire UMR-CNRS 5624, Université de Pau et des Pays de l'Adour, 64013, PAU, and

${ }^{3}$ Centre Interuniversitaire de Recherche et d'Ingéniérie des Materiaux, UMR-CNRS 5085, Université Paul Sabatier, 31062 Toulouse, France

Keywords: A. Carbon nanotubes; C. Thermal analysis; D. Functional groups.

Because of their unique physical, chemical, and structural properties, carbon nanotubes (CNT) are playing an increasingly important role in the development of new engineering materials [1]. Across many different applications, CNT/polymer composites have been extensively studied [2]. The key problem for $\mathrm{CNT} /$ polymer composite elaboration is the dispersion, compatibilization, and stabilization of the CNT in the polymer matrix. To solve this problem, a structure with di-block copolymers, one with a good affinity to CNT (monomer M1), the other being the matrix (monomer M2), is proposed in this study, as shown on the two steps mechanism of figure 1.

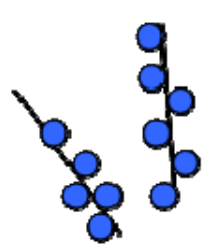

Monomer Mif adsorbed on the manohbes surface

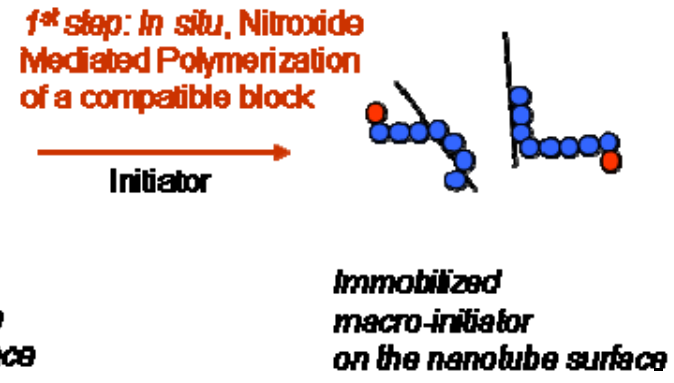

f*k stap: In silu, Niluoxide Madiabad Pohmprizalion Iniliebor

macroinitiator on the nanobube surface

Figure 1: Schematic illustration of the synthetic process $-1^{\text {st }}$ step: NMP of monomer M1; $2^{\text {nd }}$ step: use of the macroinitiator for matrix formation.

\footnotetext{
* Corresponding author Tel.: +33-559-407708; fax: +33-559-407744

E-mail address: christelle.guerret@univ-pau.fr
} 
In the present paper, we report experiments based on in situ Nitroxide Mediated Polymerisation (NMP). The NMP method is indeed more attractive than other synthetic methods, such as the Atom Transfer Radical Polymerisation (ATRP), to obtain CNT/polymer composites with controlled polymer architecture [3]. The main advantage of our synthetic route is that it does not involve any indispensable CNT pre-treatment or functionalization. In addition, polymerisation of hydrophilic polymers, such as acrylic acid, is possible with the NMP method, but not with the ATRP. Moreover we used an alcoxyamine NMP initiator (I), 2-methyl-2- [N-tertbutyl-N- [diethoxyphosphoryl-2, 2-di methyl propyl) aminoxy] propionic acid, that allows the synthesis of well-defined block or gradient copolymers and the control of the polymer polydispersity [4].

In this study, the CNT were double-walled carbon nanotubes (DWNT), which were synthesized by a catalytic chemical vapour deposition (CCVD) method. The process of preparation and purification was described in details elsewhere [5]. Statistical studies of TEM images of individual CNT have shown that about $80 \%$ were double walled, with diameters ranging mainly between 1 and $3 \mathrm{~nm}$ and lengths up to $100 \mu \mathrm{m}$.

The main steps of our synthetic route are as follows. In the first step, we polymerise in situ short chains of the first block, which could play an important role in the stabilization of the DWNT dispersion. A pre-composite CNT-PM1 is thus obtained. Two types of monomers M1 have been chosen, leading respectively to a hydrophilic first block (polyacrylic acid PAA) or a hydrophobic first block (polystyrene PS). In a second step, the presence of the stable nitroxide radical on the DWNT surface makes it possible to reinitiate the polymerisation of different monomers M2 for the preparation of the DWNT/polymer final composites CNT-PM1-PM2.

Pristine DWNT $(0.2 \mathrm{~g})$ were dispersed by sonication in 1,4 -dioxane $(15 \mathrm{ml})$ during 1 hour. A determined amount of the first monomer M1 (2 g) was added to the dispersion and was kept under stirring for one hour to promote the monomer adsorption onto CNT surface. Then, a respective amount of the initiator was added with ratio $[\mathrm{M} 1] /[\mathrm{I}]=300$. Deoxygenation was performed by nitrogen bubbling for $30 \mathrm{~min}$ directly before polymerisation and the reactor was heated to $115^{\circ} \mathrm{C}$ for different polymerization times, leading to various molecular weights of the first polymer block. 
DWNT/polymer pre-composites were synthesized with different CNT contents, measured by Thermo Gravimetry Analysis at $10{ }^{\circ} \mathrm{C} / \mathrm{min}$ in nitrogen on TA Instruments TGA2950. Quantitative amounts of DWNT in pre-composites were evaluated after each step of the polymerisation, ranging from $23 \% \mathrm{wt}$ to $43 \% \mathrm{wt}$ in the case of DWNT-PAA pre-composite, and from $2 \% \mathrm{wt}$ to $10 \% \mathrm{wt}$ in the case of DWNT-PS pre-composite. Immediately after the polymerisation of the pre-composite, the mixture was cooled to room temperature. Supplementary amounts of 1,4-dioxane and second monomer M2 were added and the reaction was continued at $115{ }^{\circ} \mathrm{C}$, for polymerisation times ranging from $30 \mathrm{~min}$ to $300 \mathrm{~min}$. We obtained composites with CNT final amounts from 0,3 to 4,7 $\mathrm{wt} \%$. As an example, methyl acrylate (MA) in ratio $[\mathrm{M} 1]:[\mathrm{M} 2]=1: 9$ was chosen as second monomer M2, for having an elastomer matrix.

Three different samples, namely pure DWNT, DWNT-PS and DWNT-PAA pre-composites, were analysed by X-ray photoelectron spectroscopy XPS, using a Kratos 165 Axis Ultra. This characterisation technique allowed to investigate the changes of atomic and electronic structures of the DWNT after the first block polymerisation. Figure 2 shows the deconvolution of the $\mathrm{C} 1 \mathrm{~s}$ peak into five main contributions noted from (a) to (e) for increasing energies. The (a) peak of the pure DWNT is narrow and very similar to that of graphitic carbon $(284.2 \mathrm{eV})$. It demonstrates that the CNT are composed of graphene layers of good crystallinity. The asymmetry on the high energy side of the $\mathrm{C} 1 \mathrm{~s}$ peak corresponds to a second peak (b) at $285.0 \mathrm{eV}$. It may be related to some structural defects at the surface of the graphitic sheet (carbon atoms in another state than the typical graphitic pure $\mathrm{sp}^{2}$ one). The (e) peak, commonly related to the $\pi-\pi^{*}$ transition levels (free electrons of the graphitic plane) is observed at c.a. $291 \mathrm{eV}$. Peaks (c) and (d), respectively at $286.3 \mathrm{eV}$ and $287.8 \mathrm{eV}$, correspond to $\mathrm{C}-\mathrm{O}$ and $\mathrm{C}=\mathrm{O}$ bonds, due to the presence of c.a. $2.6 \%$ of oxygen onto the surface of the DWNT. 

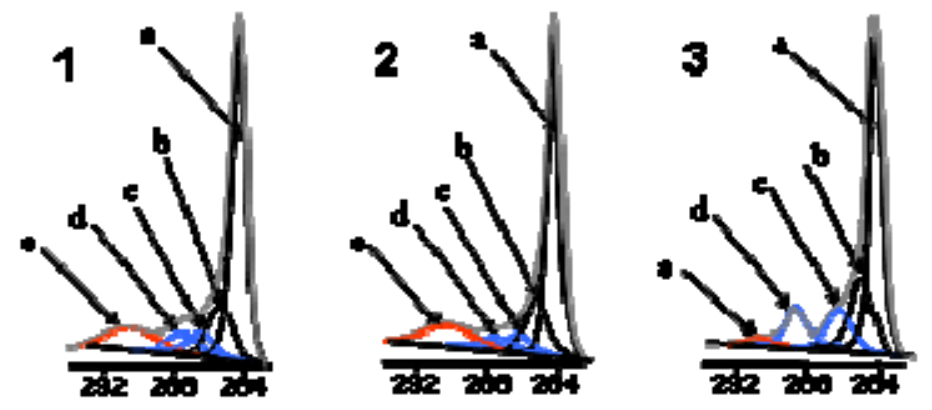

Binding Finergy (eV)

Figure 2: XPS Spectra of C1s for (1) pure DWNT, (2) DWNT-PS, (3) DWNT-PAA composites.

For the DWNT-PS pre-composite the surface oxygen amount decreases slightly, due to the presence of PS. On the contrary, it increases for the DWNT-PAA pre-composite to approximately $30 \%$. This can be related to carboxylic groups of the PAA chains, with an intense peak at c.a. $288.5 \mathrm{eV}$. The spectrum of the DWNT-PS pre-composite showed the same shape as for the pure DWNT: one can see the presence of the $\pi-\pi^{*}$ transition peak which reveals weak interactions between CNT and polymer chains. In the case of the DWNT-PAA pre-composite, the disappearance of the $\pi$ - $\pi^{*}$ transition levels indicates that some covalent bonds should have been formed between CNT surface and carboxyl functions of the PAA. These XPS spectra provide the first evidence of the stronger interactions between DWNT and PAA than with PS.

In order to confirm this result, desorption experiments were carried out. A DWNT-PAA precomposite sample $(0.1 \mathrm{~g})$ was washed 3 times with $50 \mathrm{ml}$ of ethanol, and then dried under vacuum at $50{ }^{\circ} \mathrm{C}$; the remaining polymer amount was determined by TGA to $20.54 \mathrm{wt} \%$. The same procedure, performed on a DWNT-PS pre-composite, washed with toluene, leads to a residual polymer quantity of $3.69 \mathrm{wt} \%$. From XPS analysis and desorption experiments, we can conclude that the carboxylic groups of the AA are chemisorbed onto the DWNT, via interaction with hydroxyl and carboxylic functions present onto their surface. Moreover, formation of the chemical bonds can take place during the polymerisation at $115^{\circ} \mathrm{C}$ by condensation, which is not possible with the PS block.

Further evidence of the strong interactions between DWNT and PAA is provided by the improvement of the DWNT dispersion stabilization. It is shown by the experiment presented in 
Figure 3. Sample 1 (on the left) is composed of pristine CNT dispersed in water under sonication, during 1 hour, and placed in a bottle containing toluene. After mixing for 10 minutes, the sample was left for 1 hour and one can observe that DWNT moved from the water to the toluene. Sample 2, on the right, corresponds to the DWNT-PAA pre-composite redispersed in water by simple mechanical stirring, and also mixed with toluene. We can see that DWNT remain in water, confirming the significant chemical interactions between the DWNT and the polar groups of the PAA.

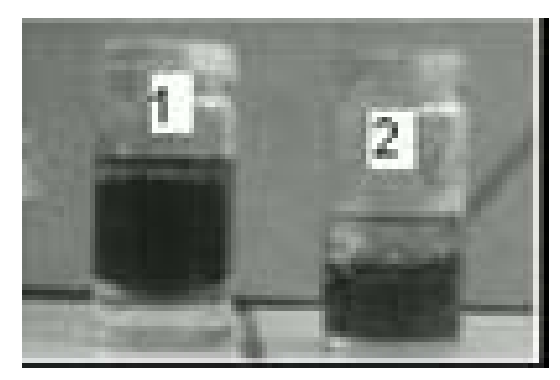

Figure 3: Distribution of the DWNT in water/toluene mixture, (1) pure CNT; (2) CNT modified with PAA

Finally, from the DWNT-PM1 pre-composites, we performed in situ NMP of the DWNT-PM1-PM2 final composites. This second step was initiated with PM1-based macro-initiator, immobilized or not onto the CNT. The TGA studies of synthesized DWNT-PM1-PMA composites (figure 4) showed that the thermal degradation of the polymer matrix have been completed at $440^{\circ} \mathrm{C}$ in the DWNT-PSPMA composite. The full matrix decomposition of the DWNT-PAA-PMA composite occurred at a higher temperature $\left(575^{\circ} \mathrm{C}\right)$. This result is consistent with the presence of an organic phase (c.a.12 \%) strongly interacting with the CNT surface. Thus the polymer might be grafted onto the DWNT. 


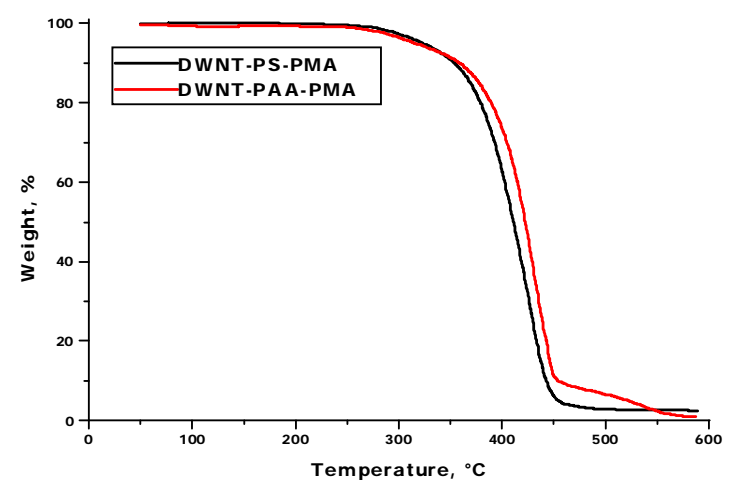

Figure 4: TGA traces of the DWNT/polymer composites

Electrical and mechanical studies of these final composites are in progress. First four point probes conductivity tests show that the DWNT-PAA-PMA composites exhibit good conductivity around $0.3 \mathrm{Scm}^{-1}$ for the highest CNT contents and a percolation threshold for a CNT amount around $2 \mathrm{wt}$ $\%$.

In summary, for the first time DWNT/polymer composites were synthesized by in situ NMP. Our block copolymer synthetic method allows elaborating well-dispersed CNT in various polymer matrices, as the first block is strongly interacting with the CNT surface. Such composites could also be used as compatibiliser to improve the dispersion of CNT in different industrially produced polymer matrices.

Acknowledgements. We thank the CNRS for the financial support. We acknowledge Atofina Research Centre for supplying initiator, and, especially, Dr O.Guerret for fruitful discussions.

\section{References.}

[1] Ajayan P.M. Chem. Rev. Nanotubes from Carbon. 1999; 99: 1787-800.

[2] Sinnot S.B, Andrews R. Carbon Nanotubes: Synthesis, Properties, and Applications. Critical Reviews in Solid State and Materials Sciences, 2001; 26: 145-249 
[3] Baskaran D, Mays J.W, Bratcher M.S. Polymer-grafted Multiwalled Carbon Nanotubes through Surface-Initiated Polymerisation. Angew. Chem. Int. Ed. 2004; 43: 2138-42.

[4] Couturier J.L, Guerret O, Bertin D, Gigmes D, Marque S, Tordo P, Chauvin F, Dufils P.E. Patent of France WO 2004014926, 2004

[5] Flahaut E, Bacsa R, Peigney A, Laurent C. Gram-scale CCVD Synthesis of Double-Walled Carbon nanotube Chem. Comm. 2003; 12, 1442-3.

\section{Figures captions:}

Figure 1: Schematic illustration of the synthetic process $-1^{\text {st }}$ step: NMP of monomer M1; $2^{\text {nd }}$ step: use of the macroinitiator for matrix formation.

Figure 2: XPS Spectra of C1s for (1) pure DWNT, (2) DWNT-PS, (3) DWNT-PAA composites.

Figure 3: Distribution of the DWNT in water/toluene mixture, (1) pure CNT; (2) CNT modified with PAA;

Figure 4: TGA traces of the DWNT-polymer composites 